\title{
Sustained activation of the HER1-ERK1/2-RSK signaling pathway controls myoepithelial cell fate in human mammary tissue
}

\author{
Lejla Pasic, ${ }^{1,2}$ T.S. Karin Eisinger-Mathason, ${ }^{1,2}$ Bisi T. Velayudhan, ${ }^{1,2}$ Christopher A. Moskaluk, ${ }^{3}$ \\ David R. Brenin, ${ }^{4}$ Ian G. Macara, ${ }^{1,2,5}$ and Deborah A. Lannigan ${ }^{1,2,5,6}$ \\ ${ }^{1}$ Department of Microbiology, University of Virginia, Charlottesville, Virginia 22908, USA; ${ }^{2}$ Center for Cell Signaling, University \\ of Virginia, Charlottesville, Virginia 22908, USA; ${ }^{3}$ Department of Pathology, University of Virginia, Charlottesville, Virginia \\ 22908, USA; ${ }^{4}$ Department of Surgery, University of Virginia, Charlottesville, Virginia 22908, USA
}

Human mammary glands arise from multipotent progenitor cells, which likely respond both to cell-autonomous and to extrinsic cues. However, the identity of these cues and how they might act remain unclear. We analyzed HER1 ligand effects on mammary morphogenesis using a three-dimensional organoid model generated from human breast tissue that recapitulates both qualitatively and quantitatively the normal ductal network in situ. Strikingly, different HER1 ligands generate distinct patterns of cell fate. Epidermal growth factor (EGF) causes a massive expansion of the myoepithelial lineage. Amphiregulin, in contrast, enables normal ductal development. These differences cannot be ascribed to preferential apoptosis or proliferation of differentiated cell populations, but are dependent on HER1 signal intensity. Inhibition of the extracellular signal-regulated kinase 1/2 (ERK1/2) effector RSK prevents the EGF-induced myoepithelial expansion. Notably, mouse mammary organoids are much less responsive to HER1 ligands. Little is known about the myoepithelial lineage or about growth factor effects on mammary progenitor differentiation, and our studies provide an important window into human mammary development that reveals unexpected differences from the mouse model.

[Keywords: myoepithelial; breast; organoid; HER1; ERK1/2; RSK]

Supplemental material is available for this article.

Received December 22, 2010; revised version accepted June 14, 2011.

Understanding the initiation and progression of breast cancer requires knowledge of the normal development of the mammary ductal network. The ducts are comprised of a luminal epithelial layer overlaid by a basal layer, which consists mainly of myoepithelial cells. A multipotent mammary stem cell acts as a common progenitor for the luminal and myoepithelial lineages (Siegel and Muller 2010). Notch signaling acts to commit progenitors to the luminal lineage (Bouras et al. 2008; Raouf et al. 2008; Yalcin-Ozuysal et al. 2010), but very little is known about the mechanisms regulating the formation of myoepithelial cells. Stem cells and other progenitors are believed to reside in the basal layer, and our lack of understanding of the myoepithelial differentiation pathway inhibits our ability to separate and study these different cell types (Lim et al. 2010).

\footnotetext{
${ }^{5}$ These authors contributed equally to this work.

${ }^{6}$ Corresponding author.

E-mail dal5f@virginia.edu.

Article is online at http://www.genesdev.org/cgi/doi/10.1101/gad.2025611.
}

The human epidermal growth factor receptor (HER1;EGFR) appears to have an early function in human duct development, as it is observed at low levels throughout the primary breast outgrowth by 14 wk of gestation. Terminally differentiated myoepithelial cells, as detected by smooth muscle actin (SMA) staining, are present at 22 wk of gestation (Jolicoeur et al. 2003; Friedrichs et al. 2007). The intensity of HER-1 staining increases during development, but by midgestation is observed only in the myoepithelial layer (Santini et al. 2002). However, based on mouse studies, the importance of HER1 to mammary development remains unclear. Elegant transplant studies using neonatal mammary glands from EGFR knockout mice revealed that, although stromal EGFR was essential for ductal development, epithelial EGFR was not required (Wiesen et al. 1999). However, expression of a dominantnegative EGFR in mammary epithelia has been found to inhibit ductal development (Xie et al. 1997). A possibility that was not excluded in the transplantation studies is that other EGFR family members, ErbB3/HER3 or ErbB4/ HER4, compensated for the loss of EGFR, perhaps by 
dimerizing with ErbB2/neu-2/HER2. ErbB3 and ErbB4 are normally absent during early ductal development /Schroeder and Lee 1998), but might have been up-regulated in the absence of EGFR. Moreover, epithelial expression of ErbB2 is necessary for ductal extension (Jackson-Fisher et al. 2004; Andrechek et al. 2005).

Using a three-dimensional (3D) ex vivo model system derived from breast tissue, we found that HER1 signaling is crucial to normal human duct development and, unexpectedly, that sustained activation of HER1 signaling through extracellular signal-regulated kinase 1/2 (ERK1/2)RSK controls myoepithelial lineage specification. Moreover, we discovered significant differences in the HER1 ligand requirements between human and mouse mammary organoids, which suggest the need for a careful evaluation of studies employing mouse models of breast cancer.

\section{Results}

Amphiregulin (AREG), in combination with an FGFR2 ligand, is necessary for normal human

ductal development

To study the development of the human mammary ductal system in vitro, we adapted procedures used for the culture of primary mouse mammary organoids (Hirai et al. 1998). To create the human breast organoid model (breastoid), we obtained tissue from breast reduction surgery or from the normal margins that were removed during breast cancer surgery. The only selection criterion for tissue was that the patient could not have obtained prior chemotherapy. Regardless of age or race of origin of the patient (Supplemental Table 1), all samples generated breastoids that were able to proliferate and develop buds (Supplemental Fig. 1). While mouse mammary organoids grow in response to the addition of either HER1/EGFR or FGF receptor 2 (FGFR2) ligands alone (Simian et al. 2001; Sternlicht et al. 2005; Fata et al. 2007; Xian et al. 2007), the human breastoids grew only in response to HER1 ligands (Supplemental Fig. 2A,B). Interestingly, using histological analysis, we observed that only the HER1 ligand AREG, in combination with an FGFR2 ligand, enabled the formation of an organized ductal network comprised of a single inner layer of luminal cells and a single outer layer of myoepithelial cells (Fig. 1, cf. A and B; Supplemental Fig. 2C-E). In the presence of AREG plus FGF2/FGF7, the tight junction marker ZO-1 correctly localizes at the apical boundaries of luminal epithelial cells and the majority of the cells in the luminal layer express K18 (Supplemental Fig. 2E). Note that the breastoids tend to compress during fixation/sectioning, probably because Matrigel is more compliant than the endogenous extracellular matrix. Additionally, a subpopulation of luminal cells in the breastoids expresses estrogen receptor $\alpha\left(E R \alpha^{+}\right)$at a frequency similar to that found in sectioned breast tissue (Supplemental Fig. 2E). As for breast tissue in situ, the myoepithelial layer of the breastoids is comprised mostly of $\mathrm{K} 14^{+} \mathrm{K} 5^{+} \mathrm{p} 63^{+}$triple-positive cells (Fig. 1A; Supplemental Fig. 2D,E). These cells also express SMA (Supplemental Fig. 2E). As in normal breast tissue, we observed a few $\mathrm{K}^{+} 4^{+} \mathrm{SMA}^{-}$cells scattered within the myoepithelial layer and some $\mathrm{K}^{+} \mathrm{K} 14^{+}$dual-positive cells within the luminal layer. We quantified the relative abundances of the various cell types in both the tissue and breastoids, and took $P$-values $\leq 0.01$ as being physiologically significant. As determined by the F-test, there was no statistical difference between the variability of breastoids derived from a single patient as compared with those derived from different patients (Supplemental Table 2). Therefore, we treated observations made on individual breastoids as independent data points. The medians of each condition are shown, as outliers do not alter these values. Strikingly, AREG, in combination with FGF2/7, produced an almost exact match to the distribution of cell types found in normal breast tissue in situ (Fig. 1C; Supplemental Fig. 2F,G). Thus, although FGFR2 ligands alone do not support growth, they are necessary for proper ductal formation. We conclude from this comprehensive and quantitative analysis that AREG, in combination with an FGFR2 ligand, recapitulates human mammary morphogenesis with remarkably high fidelity.

EGF causes an early expansion of $\mathrm{K} 14^{+}$cells at the expense of the dual-positive $\mathrm{K}^{+} 4^{+} \mathrm{K} 8^{+}$pool

Unexpectedly, although the ductal structures that develop in EGF and TGF $\alpha \pm$ FGF2/7 appear similar by differential interference contrast microscopy (DIC) to the AREG/FGF breastoids, they are highly abnormal at the cellular level, being filled with $\mathrm{K} 14^{+} \mathrm{p} 63^{-}$cells (Fig. 1A; Supplemental Fig. 2C,D). These cells are also positive for K5 (Supplemental Fig. 2D). To understand the mechanism underlying the differences in breastoid morphology caused by the HER1 ligands, we analyzed the breastoids at different times after culturing. Two important differences were observed between breastoids treated with EGF versus those treated with AREG. First, at the earliest time point (day 3), the proportion of dual-positive $\mathrm{K}^{+}{ }^{+} 14^{+}$cells is higher for breastoids grown in the presence of EGF (Fig. 2A,B; Supplemental Fig. 3). Second, the proportion of $\mathrm{K}^{+}$single-positive cells decreases significantly over time in EGF and remains at a low level for at least $29 \mathrm{~d}$ (Figs. 1C, 2A,B). Concurrently, K14 ${ }^{+}$ single-positive cells increase by $\sim 50 \%$, while the $\mathrm{K} 8^{+} \mathrm{K} 14^{+}$dual positives fall by approximately sevenfold. In contrast, only minor changes occur in the proportions of the various cell types over the time course for AREG plus FGF2/7 (Figs. 1C, 2A,B).

Taken together, these results suggest that EGF expands the $\mathrm{K}^{+} \mathrm{K} 14^{+}$dual-positive precursor population and pushes it to differentiate with abnormally high frequency along the myoepithelial lineage. However, an alternative hypothesis is that the differences in $\mathrm{K}_{1} 4^{+}$populations between EGF- and AREG-treated breastoids arise because of effects on proliferation or apoptosis of specific cell lineages.

\section{Proliferation and apoptosis rates are similar for EGF versus AREG}

To determine the fraction of proliferating cells for each cell type, we costained with the proliferation marker 
A

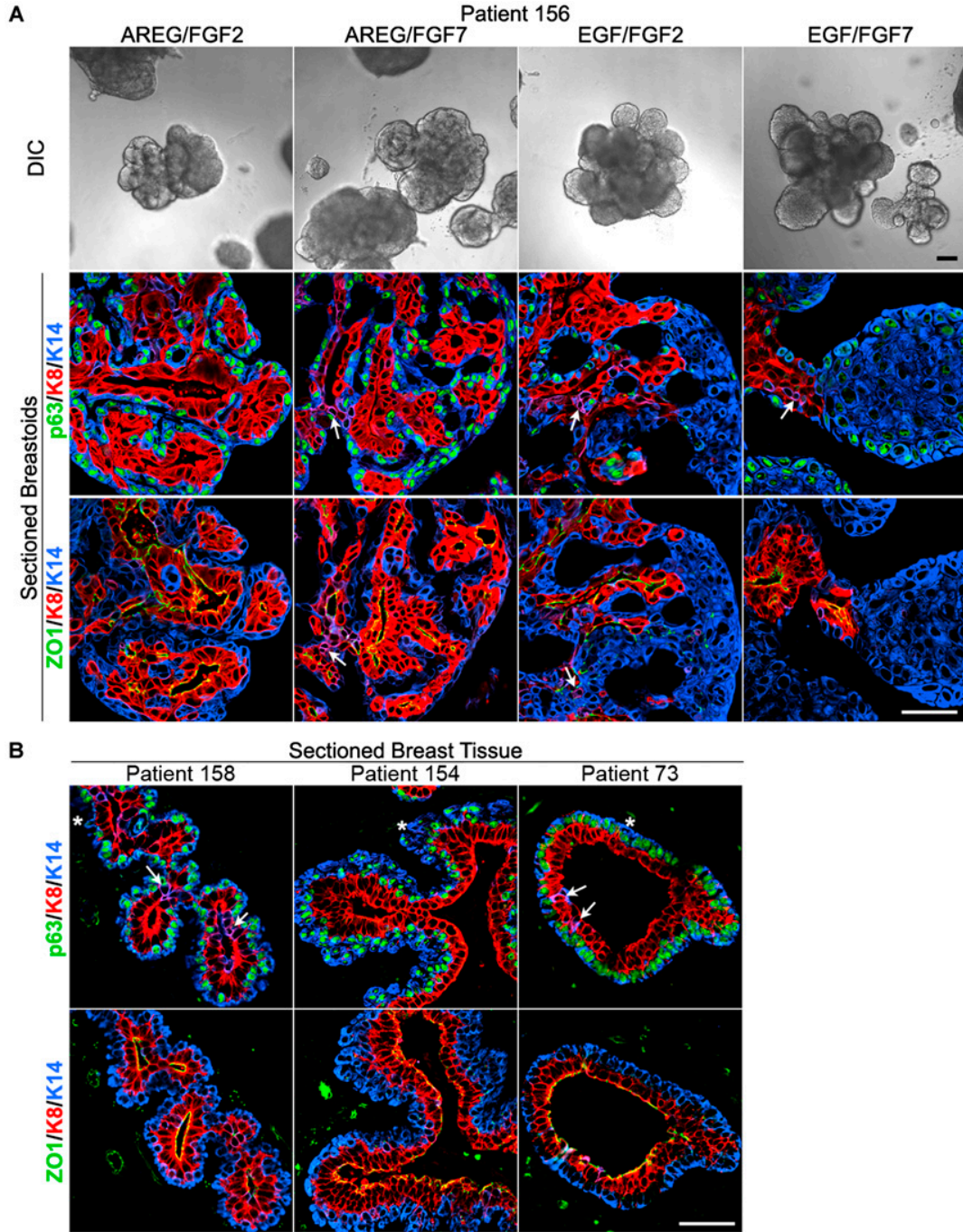

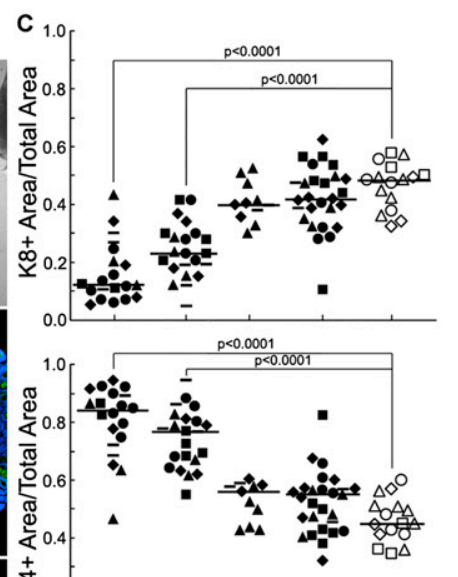

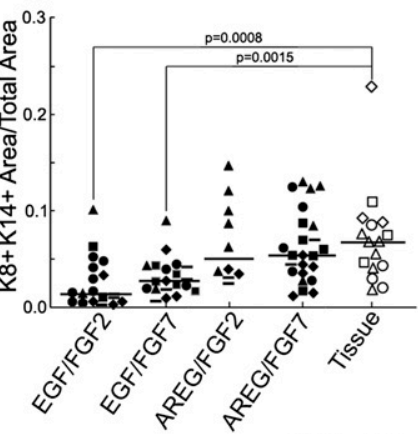

Patient 80 - Patient 87 Patient 182 -Patient 226 口Patient 73 $\triangle$ Patient 154 $\diamond$ Patient 158 opatient 266

Figure 1. AREG and an FGFR2 ligand recapitulate the ductal structure observed in situ in the human breast. (A) Representative DIC images and sections of immunostained paraffin-embedded breastoids at $29 \mathrm{~d}$ after culturing in response to the indicated growth factor combinations. Immunostained for luminal epithelial (K8 [red]), myoepithelial (K14 [blue]), and p63 [green]), and the tight junction marker ZO-1 (green). Arrows indicate dual-positive $\mathrm{K} 8{ }^{+} \mathrm{K} 14^{+}$cells. FGF2 was used at $2 \mathrm{nM}$ and all growth factors were used at $5 \mathrm{nM}$. Bars: DIC, $100 \mu \mathrm{m}$; sections, $50 \mu \mathrm{m}$. (B) Representative sections of immunostained paraffin-embedded breast tissue were obtained from the normal margin of a breast cancer (158) or from breast reduction surgeries (154 and 73). Asterisks indicate $\mathrm{K} 14^{+} \mathrm{p} 63^{-}$cells. Bar, 50 $\mu \mathrm{m} .(C)$ Scatter plot showing the fraction of different cell types that comprise the ductal structure of breast tissue or breastoids. The bar represents the median. $F$-test of data (Supplemental Table 2) showing that intrapatient and interpatient variability are not statistically different. Statistical significance was determined using the Student's $t$-test and all $P$-values $\leq 0.01$ were reported.

Ki-67. The overall proliferation rates were remarkably similar for EGF and AREG in combination with FGF2/7 (Fig. 3A; Supplemental Fig. 4A,B). In addition, the proliferation rate of the $\mathrm{K} 8^{+}$cells did not vary significantly for any of the treatments (Fig. 3A; Supplemental Fig. $4 \mathrm{~A}, \mathrm{~B})$. To detect proliferation of the myoepithelial lineage, we used costaining with p63 and Ki67 because of the ease of scoring proliferating nuclei. Note that until day 10, K14 and p63 almost completely colocalize (Supplemental Fig. 4C) for all growth conditions, which validated our analysis method. The proliferation rates of $\mathrm{p} 63^{+}$cells in response to EGF versus AREG were similar over the entire time course (Fig. 3A; Supplemental Fig. 4A,B). In particular, on days 3 and 7, the proliferation rates of $\mathrm{p} 63^{+}$ cells are similar for all growth factor conditions (Fig. 3A; Supplemental Fig. 4A,B). This time frame coincides with the increase in the percentage of $\mathrm{K}^{+} 4^{+}$cells observed with EGF in comparison with AREG (Fig. 2B). Thus, differences in proliferation do not account for the higher percentage of $\mathrm{K} 14^{+}$cells observed with EGF compared with AREG. Apoptosis, detected by staining for cleaved caspase 3, was a very rare event under all conditions, and we could detect no differences (Supplemental Fig. $4 \mathrm{D})$. We hypothesize, therefore, that EGF perturbs cell fate determination, and that this mechanism-rather than changes in proliferation or apoptosis-accounts 

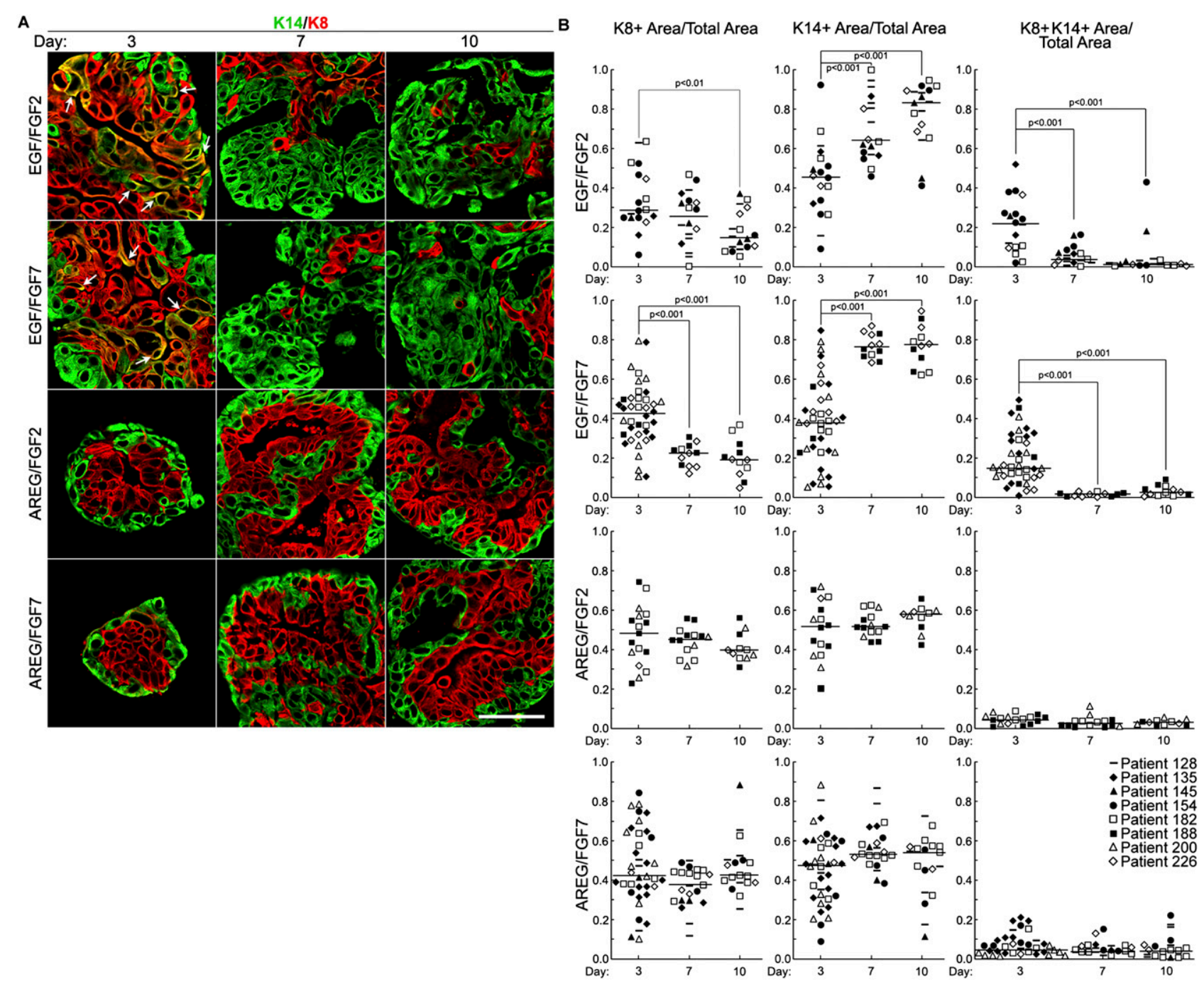

Figure 2. EGF alters ductal morphology early in development. $(A)$ Representative images of immunostained paraffin-embedded breastoids after culturing in various growth factor combinations for differing lengths of time. The arrows show dual-positive $\mathrm{K} 8^{+} \mathrm{K} 14^{+}$ cells. Bar, $50 \mu \mathrm{m}$. (B) Scatter plots showing the percentage of different cell types at the indicated times after culturing in various growth factor combinations. The bar represents the median. F-test of data (Supplemental Table 3) showing that intrapatient and interpatient variability are not statistically different. Statistical significance was determined using the one-way analysis of variance (ANOVA) and all $P$-values $\leq 0.01$ were reported.

for the abnormal duct morphology compared with AREG.

The loss of dual-positive $\mathrm{K} 8^{+} \mathrm{K} 14^{+}$cells and expansion of the myoepithelial population $7 \mathrm{~d}$ after addition of EGF suggests that these $\mathrm{K} 8^{+} \mathrm{K} 14^{+}$cells might be bipotent. If so, it should be possible to switch their fate by changing the culture conditions at day 3 from EGF to AREG. Consistent with this hypothesis, the shift to AREG restored in the majority of breastoids the normal distribution of luminal/myoepithelial cells (Fig. 3B). To determine whether differentiated myoepithelial cells can switch fates, we maintained the breastoids in EGF until day 7 and then shifted to AREG. The resulting breastoids were phenotypically similar to the breastoids continuously cultured with EGF, with no loss in the percentage of K14 ${ }^{+}$cells (Fig. 3B). Thus, by day 7 , the cells within the breastoids are committed to their fates. Together, these data are consistent with the idea that the dual-positive $\mathrm{K} 8{ }^{+} \mathrm{K} 14^{+}$cells are bipotent progenitors, although it is also possible that a basal-like progenitor can give rise to dual positives and $\mathrm{K} 8^{+}$cells.

As an alternative method of analysis, we used fluorescence-activated cell sorting (FACS) to fractionate breastoids that had been cultured for $3 \mathrm{~d}$ in AREG/FGF7 or EGF/ FGF7. Antibodies against $\alpha 6$ integrin (CD49f) and epithelial cell adhesion molecule (EpCAM) were used to sort the dissociated cells (Supplemental Fig. 5A; Lim et al. 2009). Consistent with previous data (Lim et al. 2009), $\mathrm{CD} 9 \mathrm{f}^{+} \mathrm{EpCAM}^{-}$cells express myoepithelial markers $\mathrm{K} 14$ and p63, whereas the CD49f ${ }^{-} \mathrm{EpCAM}^{+}$cells express the luminal epithelial marker K8. The CD49f ${ }^{+} \mathrm{EpCAM}^{+}$ fraction contains a mixture of cell types, which are $\mathrm{K}^{+}$, 


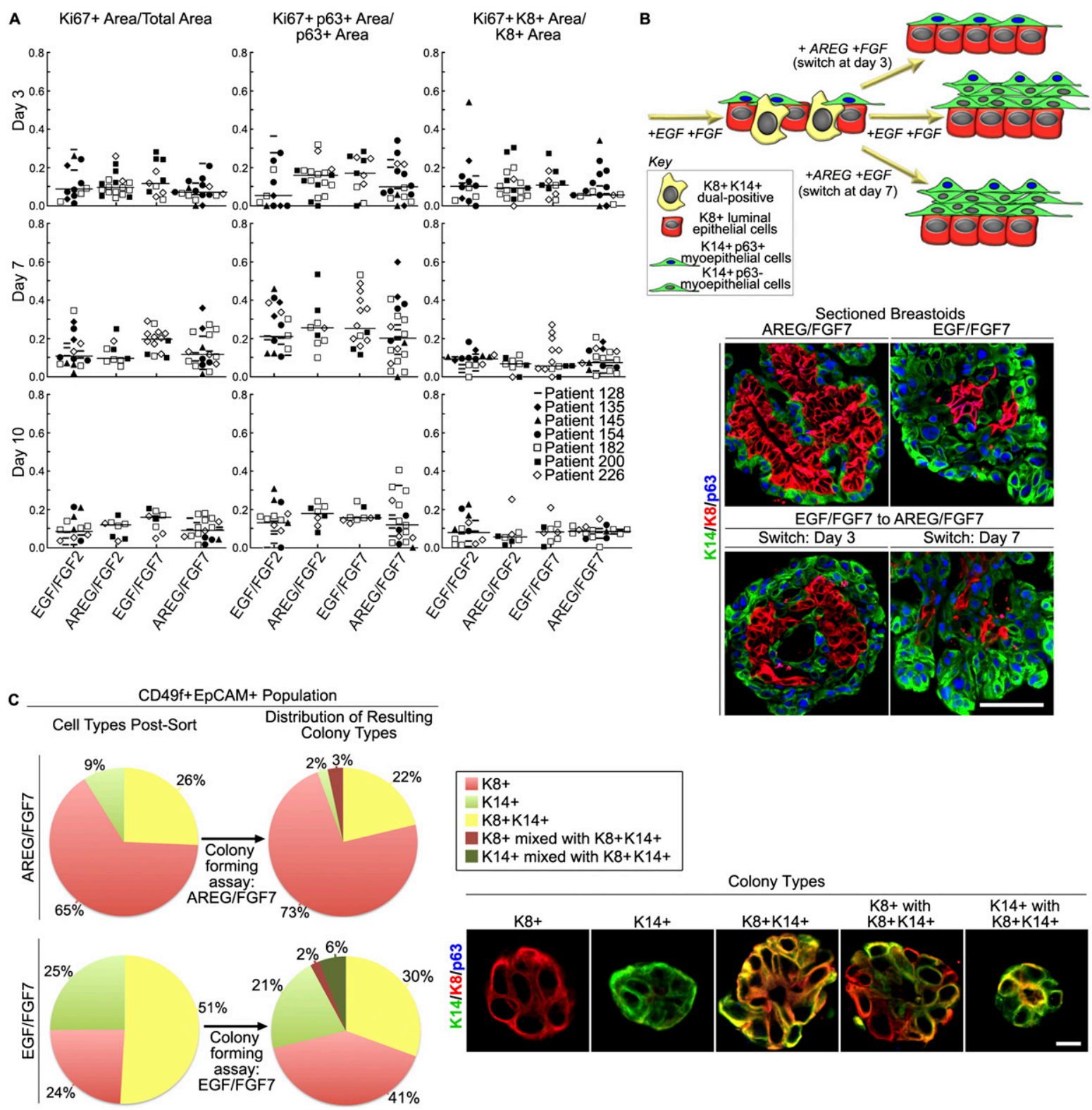

Figure 3. EGF regulates myoepithelial lineage determination. $(A)$ Comparison of the proliferation of different cell types at various times after culturing in response to different growth factor combinations. The bar represents the median. $F$-test of data (Supplemental Table 4) showing that intrapatient and interpatient variability are not statistically different. Statistical significance was determined using the Student's $t$-test and all $P$-values $\leq 0.01$ were reported. $(B)$ Schematic showing the design of the media switch experiment. Representative sections of immunostained paraffin-embedded breastoids. In the bottom panels, the medium was switched from EGF/FGF7 to AREG/FGF7 at the third or seventh day of culturing. Breastoids were cultured until day 10 . Bar, $50 \mu \mathrm{m}$. (C) Immunofluorescence analysis of cells isolated by FACS from breastoids cultured for $3 \mathrm{~d}$ in AREG/FGF7 or EGF/FGF7. Cells (5000) from the $\mathrm{CD}_{4} \mathrm{FF}^{+} \mathrm{EpCAM}^{+}$population were cultured in Matrigel and maintained in the original growth factor conditions for $7 \mathrm{~d}$. The subsequent colonies were analyzed by immunofluorescence and scored by the indicated phenotypes. Bar, $10 \mu \mathrm{m}$. Analysis was repeated on breastoids obtained from three separate patients.

$\mathrm{K} 14^{+}$, or dual-positive $\mathrm{K} 8^{+} \mathrm{K} 14^{+}$. Notably, no cells in this fraction were $\mathrm{p} 63^{+}$. Thus, the $\mathrm{K} 14^{+}$cells are not contaminants from the CD49f $\mathrm{f}^{+} \mathrm{ECAM}^{-}$fraction and represent a different cell population, which might be progenitors. The distribution of cell types obtained from breastoids cultured in AREG was $\sim 9 \% \mathrm{~K} 14^{+}$and $65 \% \mathrm{~K}^{+}$, which is similar to that for human mammary tissue obtained by $\operatorname{Lim}$ et al. $(2009)\left(\sim 6 \% \mathrm{~K} 14^{+}\right.$and $\left.\sim 90 \% \mathrm{~K} 8^{+}\right)$. Lim et al. (2009) did not analyze for dual positives. The $\mathrm{CD}_{49} \mathrm{f}^{+} \mathrm{ECAM}^{+}$fraction from breastoids cultured in EGF had $\sim 51 \%$ dual-positive $\mathrm{K}^{+} \mathrm{K} 14^{+}$cells, compared with $\sim 26 \%$ for AREG, consistent with the higher number of dual positives in EGF breastoids detected by immunofluorescence data (Fig. 2). 
We next cultured the sorted populations at clonal density using a colony-forming cell assay in Matrigel (Supplemental Fig. 5B; Lim et al. 2009). In agreement with previous results (Lim et al. 2009) the CD49f ${ }^{-} \mathrm{EpCAM}^{+}$ cells (differentiated luminal $\mathrm{K}^{+}$cells) did not generate colonies under any culture condition. The CD49f ${ }^{+} \mathrm{EpCAM}^{-}$ cells (differentiated myoepithelial cells) produced only $\mathrm{K} 4^{+}$ colonies, irrespective of the culture conditions, in which only the peripheral cells, in contact with the Matrigel, were p $63^{+}$(Supplemental Fig. 5C). We conclude that p63 ${ }^{+}$cells can generate $\mathrm{p} 63^{-}$cells, and speculate that sustained p63 expression might require integrin signaling.

The CD49f ${ }^{+}$ppCAM $^{+}$cells (progenitors) generated colonies with diverse phenotypes, which varied with the HER1 ligand used for breastoid culture (Fig. 3C). Over two-thirds of the colonies arising from CD49f ${ }^{+} \mathrm{EpCAM}^{+}$ cells in AREG, isolated from AREG breastoids, were $\mathrm{K}^{+}$ single positives. The remainder consisted of colonies of dual-positive $\mathrm{K} 8{ }^{+} \mathrm{K} 14^{+}$cells, with very few $\mathrm{K} 14^{+}$colonies or mixed colonies. Thus, AREG favors progenitor commitment to the luminal lineage, consistent with our analysis of the breastoids by immunofluorescence (Figs. $1,2)$. In contrast, for $\mathrm{CD}_{49} \mathrm{f}^{+} \mathrm{EpCAM}^{+}$cells in EGF, isolated from EGF breastoids, almost a quarter of the colonies contained only $\mathrm{K}_{1} 4^{+}$cells. About $40 \%$ were $\mathrm{K} 8^{+}$, and the remainder were $\mathrm{K} 8{ }^{+} \mathrm{K} 14^{+}$dual-positive colonies or mixed colonies of $\mathrm{K}^{+}$or $\mathrm{K}^{+} 4^{+}$and dual positives. None of the $\mathrm{K}_{1} 4^{+}$cells in these colonies expressed p63. While it is not possible to deduce the cell of origin from this analysis, the differences in cell type abundances between cultures in AREG versus EGF support the hypothesis that HER1 regulates lineage specification by human mammary progenitors.

\section{Intensity of HER1 signaling controls duct morphology}

The affinity of EGF for HER1 is 10-fold higher than that of AREG (Shoyab et al. 1989). Additionally, activation of the HER1 downstream effector ERK1/2 is more intense and prolonged with EGF as compared with AREG (Baldys et al. 2009). Thus, the differential effects of these ligands on breastoid development might reflect differences in signaling intensity through HER1. To test this hypothesis, we first asked whether EGF is more efficient than AREG in stimulating ERK $1 / 2$ activity in mammary tissue by immunoblotting breastoid extracts with an antibody that recognizes the activating phosphorylation of the Thr-Glu-Tyr motif of ERK1/2 (pERK1/2) (Her et al. 1993). A small but significant elevation in pERK was detectable in the presence of EGF versus AREG (Fig. 4A). Next, we treated the breastoids with varying concentrations of the two ligands and determined the effect on the cellular makeup of the ducts. Strikingly, a 100-fold reduction in the EGF concentration substantially increased the ratio of $\mathrm{K}^{+}$to $\mathrm{K} 14^{+}$cells and produced a normal ductal organization (Fig. 4B). Conversely, a 10-fold elevation in AREG caused overgrowth by $\mathrm{K} 4^{+}$single-positive cells. Culturing the breastoids in 0.05 nM EGF produces breastoids in which the proportions of $\mathrm{K}^{+}, \mathrm{K}_{1} 4^{+}$, and dual-positive $\mathrm{K} 8^{+} \mathrm{K} 14^{+}$cells are almost identical to those
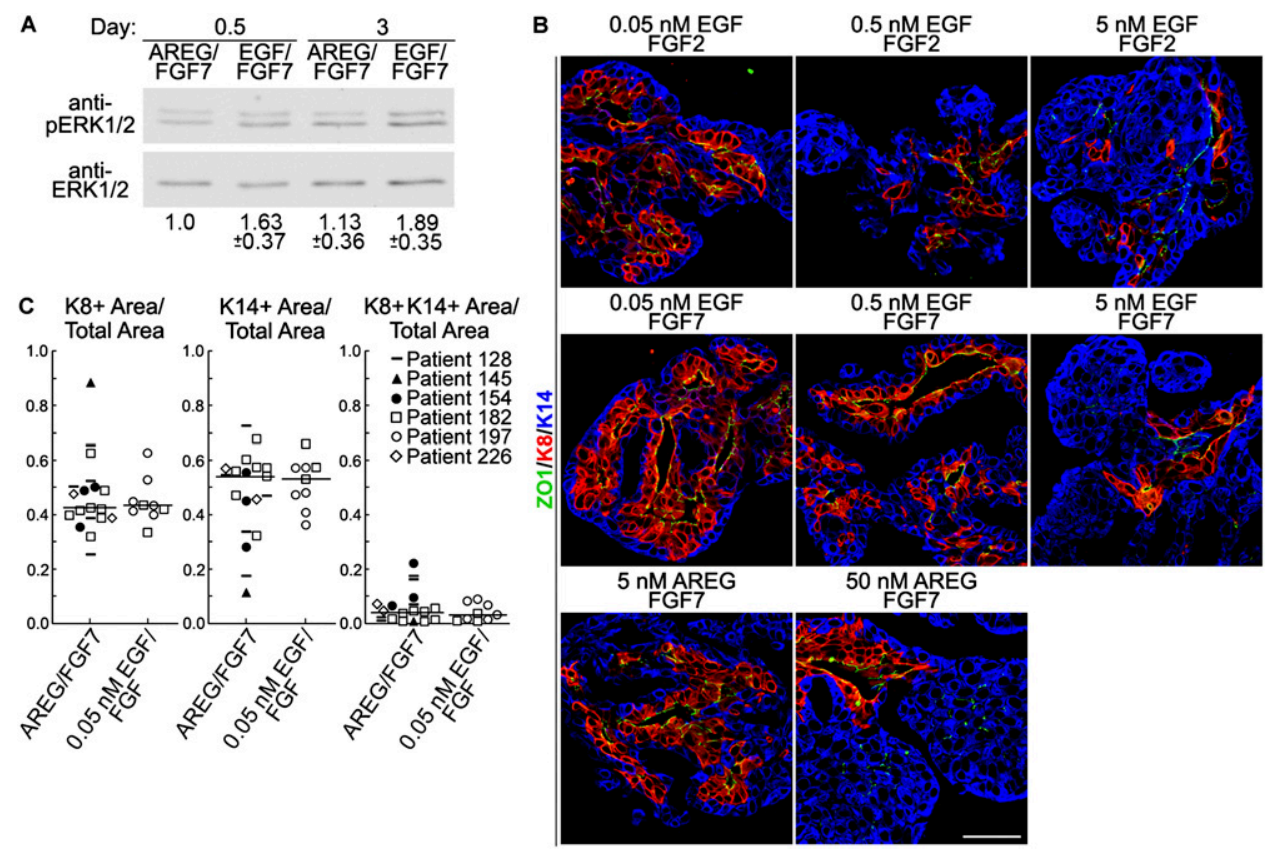

5 nMEGF
FGF7

Figure 4. Ligand affinity for HER 1 controls lineage determination. (A) Immunoblot of breastoids cultured for $3 \mathrm{~d}$ with AREG/FGF7 or EGF/FGF7. Normalized levels of pERK1/2 \pm range relative to total ERK1/2 $(n=2)$. (B) Representative sections of paraffin-embedded breastoids treated with HER1 ligands at the indicated concentration in the presence of FGFR2 ligands. After culturing for $12 \mathrm{~d}$, the breastoids were analyzed. Bar, $50 \mu \mathrm{m}$. (C) Scatter plot showing the percentage of different cell types after culturing in low-dose EGF $(0.5$ nM)/FGF7 or AREG (5.0 nM)/FGF7. 
obtained with $5 \mathrm{nM}$ AREG or observed in tissue (Figs. 1A, 4C). We conclude that low-dose EGF both qualitatively and quantitatively recapitulates normal ductal structures in situ, consistent with our hypothesis that signaling intensity via HER1 controls cell fate.

\section{HER1 signaling via ERK1/2-RSK controls myoepithelial cell fate}

To determine how HER1 signaling regulates ductal development, we first investigated the distribution of HER1 in sectioned, paraffin-embedded tissue and breastoids. HER 1 staining was present in both $\mathrm{K} 14^{+}$cells and patches of $\mathrm{K}^{+}$cells (Supplemental Fig. 6). Potentially, therefore, HER 1 signaling could occur in most luminal and myoepithelial cells.

We next asked whether we could detect differences in HER 1 signaling between the various cell types by staining for activated ERK1/2. The pERK antibody is specific because treatment of breastoids with the MEK inhibitor U0126 significantly diminished staining intensity (Supplemental Fig. 7A). Overall, ERK activity is significantly lower in luminal $\left(\mathrm{K}^{+}\right)$cells than in other cell types $\left(\mathrm{K}^{-}\right)$ (Fig. 5A). Initially, pERK levels were only $\sim 20 \%$ lower in $\mathrm{K} 8^{+}$cells versus $\mathrm{K}^{-}$cells irrespective of the HER 1 ligand, but fell further over time in culture (Fig. 5A,B). ERK activity was independent of FGF in the culture medium (Supplemental Fig. 7B). Luminal ERK activity fell more slowly for breastoids cultured with EGF than with AREG (Fig. 5A,B), perhaps because of the large number of $\mathrm{K} 8^{+} \mathrm{K} 14^{+}$dual-positive cells that are initially present in EGF breastoids, which have high pERK levels. Thus, pERK activity decreases in cells committed to a luminal epithelial cell fate, but remains high in myoepithelial cells.

Comparison of pERK levels between growth factor conditions in the immunofluorescence experiments was not performed, as it was not possible to rule out artifacts; e.g., differences in sectioning that might produce differences in signal intensity. Therefore, to test whether HER 1 signaling is required for myoepithelial lineage specification, we inhibited the ERK-RSK pathway using the RSKspecific inhibitor SL0101 (Smith et al. 2005). We reasoned that SL0101 might restore EGF-treated breastoids to a more normal phenotype by decreasing signaling through RSK. Notably, SL0101 treatment of breastoids cultured with EGF for $3 \mathrm{~d}$ reduced the number of $\mathrm{K} 8^{+} \mathrm{K} 14^{+}$dualpositive cells by threefold (Fig. 5C,D). This effect was not caused by any increase in apoptosis of breastoids treated with SL0101 (Supplemental Fig. 7C). However, after $10 \mathrm{~d}$ with SL0101 in either growth condition, the myoepithelial cells had entirely disappeared. With this extended SL0101 treatment, some apoptosis was detectable in the $\mathrm{K}^{+}{ }^{+}$cells, which might be due to the absence of RSK activity or the lack of myoepithelial cells (Supplemental Fig. 7D). We conclude that constant, high-intensity signaling through HER 1 via RSK expands the population of $\mathrm{K}^{+} \mathrm{K} 14^{+}$dual-positive cells and is essential for the specification and/or survival of the myoepithelial lineage.
Murine mammary organoids are less responsive to HER1 ligands than are human breastoids

Branching morphogenesis has been shown previously to occur in organoids obtained from mouse mammary glands in response to FGFR2 ligands, EGF, and AREG (Hirai et al. 1998; Sternlicht et al. 2005; Ewald et al. 2008; Sternlicht and Sunnarborg 2008). However, the cellular organization of these structures was not investigated. Therefore, we grew murine mammary organoids under conditions identical to those described above for the human breastoids. Consistent with the data of Sternlicht et al. (2005), but in contrast to Fata et al. (2007), we found that FGF7 and EGF each individually increased the size and branching frequency of the mouse mammary organoids (Fig. 6A). However, the organoids did not develop in the presence of AREG alone. With EGF alone, a substantial number of dual-positive $\mathrm{K} 8^{+} \mathrm{K} 14^{+}$cells were present compared with the other conditions (Supplemental Fig. 8). FGF7 alone generated very compact structures with small lumens, in contrast to those organoids that were also treated with a HER1 ligand (cf. Fig. 6B and Supplemental Fig. 7). Moreover, some epithelial cells were at the outer edge of the organoid and not surrounded by a myoepithelial layer. Strikingly, however, and in contrast to the human breastoids, FGF7 with EGF recapitulated normal ductal organization (Fig. 6B). FGF7 with AREG generated ducts that had larger lumens than FGF7 alone but still had a disorganized cellular structure with large gaps in the myoepithelial layer. These data suggest that the mouse mammary ductal system is less responsive to HER1 ligands than that of the human system.

\section{Discussion}

We describe the first defined in vitro system that quantitatively and qualitatively recapitulates with high fidelity the normal duct morphology found in situ in the human breast. This breastoid model is highly robust, and we could detect no significant differences in morphogenesis with age or race of the tissue donors. Moreover, the variance in cell type between breastoids from different patients was no greater than the variance between different breastoids from the same patient. This system permits simple manipulation of the hormonal environment and real-time imaging.

A number of other approaches have been used to study human breast ductal development. One elegant method employs humanized mice, in which both the stromal and epithelial components of human glands are transplanted into the cleared fat pads of immunocompromised NOD/ SCID mice. Cyst-like outgrowths appear after several weeks, consisting predominantly of spherical structures with hollow lumina, with some ductal structures (Kuperwasser et al. 2004). These outgrowths contain myoepithelial and luminal epithelial cells and produce milk proteins in pregnant animals; however, the structures cannot be imaged in situ, and it remains uncertain whether the outgrowths generate all of the normal cell types present in human mammary ducts. It is also unknown what specific contributions stromal cells make to the development of 
Pasic et al.

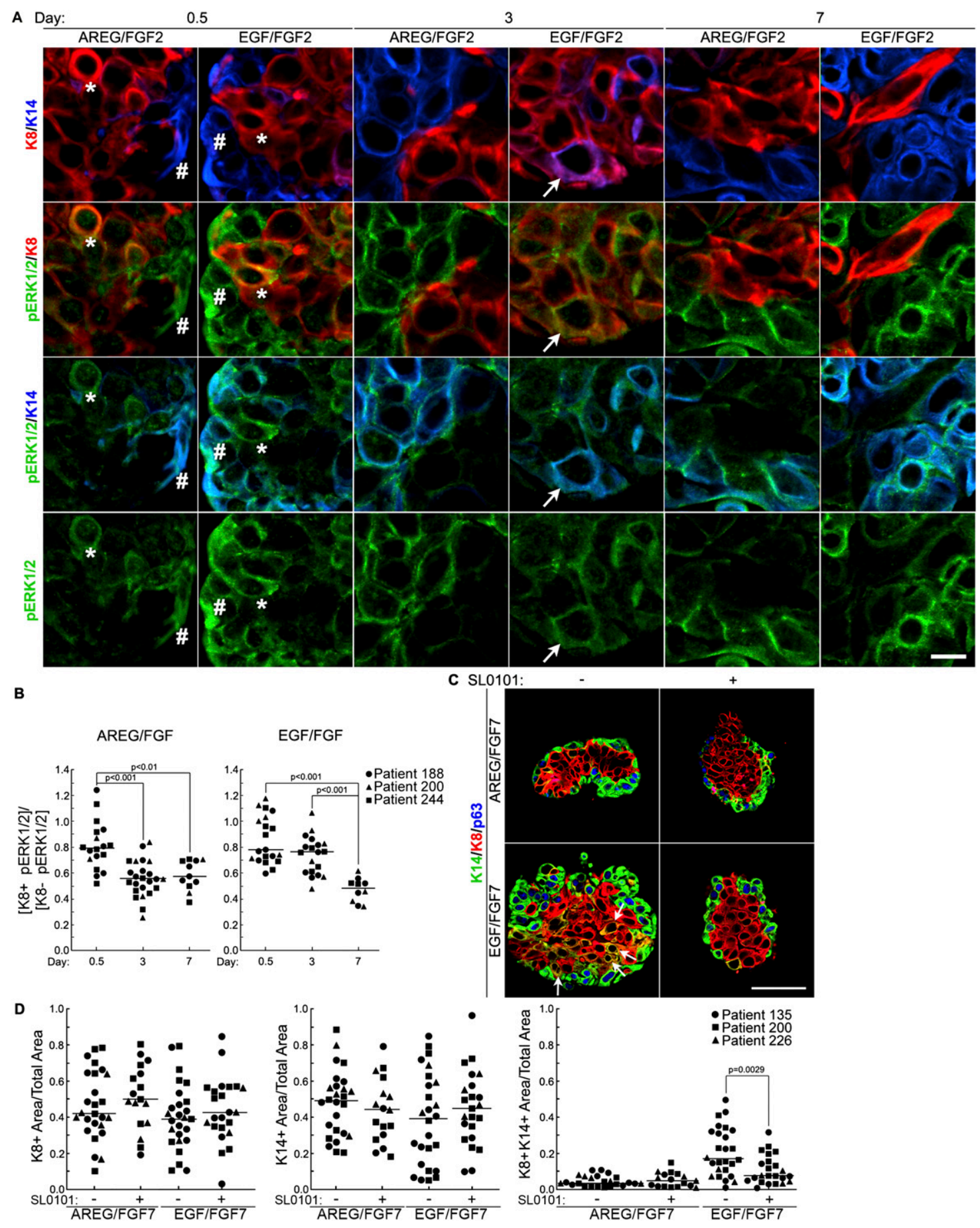

Figure 5. HER1-ERK1/2-RSK signaling regulates ductal development. (A) Representative sections of paraffin-embedded breastoids treated with varying growth factor conditions for differing lengths of time. Sections were immunostained with pERK1/2, K8, and K14.

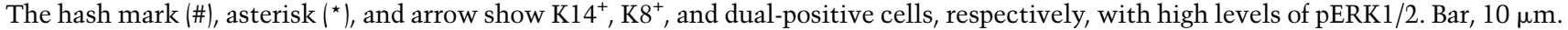
(B) Scatter plot comparing the relative proportion of pERK1/2 intensity in $\mathrm{K} 8^{+}$compared with $\mathrm{K} 8^{-}$cells after culturing in various growth factor conditions for differing lengths of time. The bar represents the median. Data using FGF2 or FGF7 were pooled. F-test of data (Supplemental Table 5) showing that intrapatient and interpatient variability are not statistically different. Statistical significance was determined using the one-way ANOVA and all $P$-values $\leq 0.01$ were reported. $(C)$ Representative images of immunostained paraffin-embedded breastoids treated with AREG or EGF with FGF7 in the presence or absence of $100 \mu \mathrm{M}$ SL0101 for $3 \mathrm{~d}$. The arrow shows dual-positive $\mathrm{K} 8{ }^{+} \mathrm{K} 14^{+}$cells. Bar, $50 \mu \mathrm{m}$. $(D)$ Scatter plot showing the percentage of different cell types after culturing in various growth factor combinations in the absence or presence of SL0101 for $3 \mathrm{~d}$. The bar represents the median. F-test of data (Supplemental Table 6) showing that intrapatient and interpatient variability are not statistically different. Statistical significance was determined using the Student's $t$-test and all $P$-values $\leq 0.01$ were reported. 
A

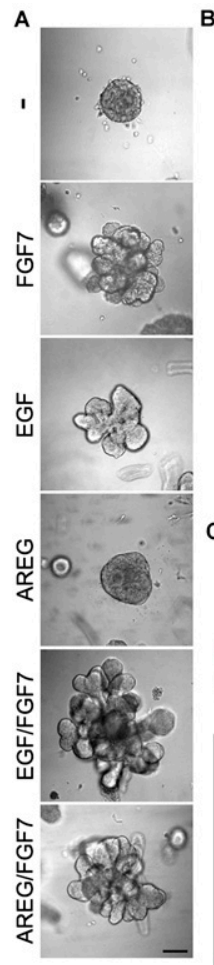

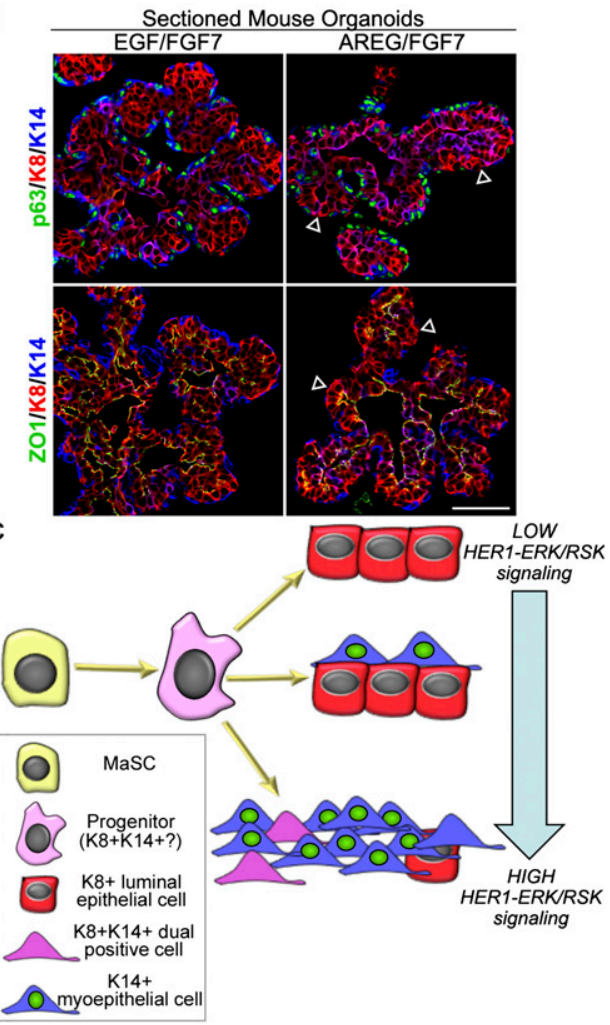

Figure 6. Mouse mammary organoids generate normal ducts in response to EGF/FGF7. (A) Representative DIC images of mouse mammary organoids at day 3 after culturing with the indicated growth factors. Bar, $100 \mu \mathrm{m}$. (B) Representative sections of immunostained paraffin-embedded mouse mammary organoids that were cultured for $7 \mathrm{~d}$. Arrowheads indicate $\mathrm{K} 8^{+}$cells that are not surrounded by $\mathrm{K} 14^{+}$cells. Bar, $50 \mu \mathrm{m}$. (C) Schematic showing the effect of HER1 signaling intensity on lineage determination in human ductal development.

the outgrowths. A 3D culture model using primary human breast epithelial cells has been reported previously (Graham et al. 2009). However, this model used an undefined culture system and the structures generated were multilayered and not polarized. Mouse models have provided a powerful means to study mammary gland development, but the extent to which they recapitulate human mammary development remains unclear. Notable differences between the two tissues include the presence of large terminal end buds in the outgrowing ducts of mouse mammary glands, the greater number of adipocytes in the mouse mammary gland, and the more fibrous environment of human breast tissue /Visvader 2009). Therefore, we believe that our breastoid model will provide an important new window into human mammary ductal development and breast cancer initiation and progression.

Using the breastoid model, we demonstrate an unexpected effect of HER1 signaling intensity on lineage specification. Importantly, the model also reveals differences in the responses to FGFR2 and HER1 ligands between mouse and human mammary tissue. Of the HER1 ligands

tested, only AREG or very low concentrations of EGF generate human mammary ducts with normal morphology, while in murine mammary organoids, high EGF is required. The effects of EGF on human mammary ductal growth were unexpected. The breastoids extend lobular structures in the presence of either EGF or AREG, and visual inspection of the intact breastoids cannot readily distinguish them. Histological analysis is essential, therefore, to determine whether $3 \mathrm{D}$ cultures are recapitulating normal morphogenesis or not. In this case, EGF generates lobules that have no lumens and are filled with myoepithelial cells. Since we could detect no differences in proliferation or apoptotic rates in the breastoids grown in EGF versus AREG, we conclude that signaling through HER1 can alter the lineage specification of a myoepithelial progenitor. Defining the mechanism by which EGF and AREG alter duct morphology is not straightforward, as the affinity, receptor recycling, and degradation rates all differ between the HER1 ligands. For example, AREG was $\sim 50$-fold less potent than EGF in stimulating HER1 activation as measured by phosphorylation of Tyr 1173 in HER1 (Baldys et al. 2009). Moreover, when EGF and AREG were added at concentrations that result in equivalent levels of HER1 activation, EGF stimulated HER1 degradation, whereas AREG promoted HER1 recycling (Baldys et al. 2009; Willmarth et al. 2009). These differences in HER1 recycling led to differing profiles of ERK1/2 activation. Because we found that high concentrations of AREG mimic the effects of EGF in expanding the myoepithelial cell pool, HER1 recycling is probably not coupled to lineage specification in the human mammary gland. Additionally, we found that myoepithelial expansion is correlated with EGF concentration, which suggests that signaling from HER1 is important for specification of the myoepithelial lineage. Consistent with this hypothesis, blockade of HER1 signaling through the ERK-RSK pathway completely eliminates myoepithelial cell formation in the breastoids. Taken together, our data suggest that the growth factor requirements for murine and human mammary glands are distinct, and that the mouse model cannot be assumed to recapitulate all aspects of human breast physiology. This difference in responsiveness to HER1 ligands might be of considerable importance in understanding the etiology of HER2 ${ }^{+}$breast cancers, because HER2 can alter signaling through HER1 (Wada et al. 1990; Haslekas et al. 2005).

The identification of progenitors for differentiated cell types is not possible without lineage tracing or clonal assays using isotypic cell populations. Consistent with the literature, the $\mathrm{CD}_{4} 9 \mathrm{f}^{+} \mathrm{EpCAM}^{+}$progenitor pool consists of at least three distinct cell types (Clayton et al. 2004; Stingl et al. 2001; Villadsen et al. 2007); thus, we cannot determine unambiguously the origin of the myoepithelial cell population in EGF-treated breastoids. Nonetheless, we speculate that the dual-positive $\mathrm{K} 8{ }^{+} \mathrm{K} 14^{+}$cells might be bipotent, based on the following observations: (1) The time course of the expansion of myoepithelial cells coincides with a decrease in the dual-positive $\mathrm{K} 8{ }^{+} \mathrm{K} 14^{+}$population in response to EGF; (2) switching from EGF to AREG at day 3 prevents the myoepithelial 
expansion and results in a normal ductal phenotype; and (3) inhibition of EGF signaling through RSK eliminates both the early expansion of dual-positive $\mathrm{K}^{+} \mathrm{K} 14^{+}$cells and the later formation of myoepithelial cells. However, it is also possible that the $\mathrm{K} 88^{+} \mathrm{K} 14^{+}$cells arise from a $\mathrm{K} 14^{+} \mathrm{p} 63^{-}$progenitor and, in AREG, rapidly mature to $\mathrm{K} 8^{+}$ luminal cells. Further FACS analysis with new surface markers will be required to distinguish these models.

To understand the molecular basis for the effects of HER1 signaling on lineage specification, we analyzed the distribution of HER1 and activated ERK1/2 in the breastoids. HER1 was found in myoepithelial cells and in a subpopulation of luminal cells. Strikingly, however, temporal activation of the ERK1/2 signaling pathway was different between these cell populations. Initially, the pERK1/2 levels were similar in the luminal, dual-positive, and myoepithelial populations. However, at later times, the levels decreased in the committed luminal epithelial lineage, but remained elevated in the myoepithelial population. Additionally, as described above, addition of a highly specific inhibitor of the RSK protein kinase blocked the EGF-dependent formation of dual-positive cells in the breastoids, and at later times resulted in the loss of all myoepithelial cells. Since RSK acts downstream from ERK1/2, these data are consistent with the idea that the formation of myoepithelial cells from a progenitor is proportional to the degree of HER1 activation (Fig. 6C).

In addition to AREG, we observed a requirement for FGF2/7 to establish correct duct structures. FGF7 selectively interacts with FGFR2IIb with a $0.1 \mathrm{nM}$ affinity (Cheon et al. 1994), and FGF2 interacts with the same receptor at a 15-fold lower affinity (Miki et al. 1992; Sher et al. 2000). Thus, the 1-5 nM concentration range used in our experiments would have been sufficient to result in the interaction of FGF2 with FGFR2IIb, and we did not observe any difference in organoid growth between the FGFR2 ligands over this range of concentrations. Since in our hands both FGF2 and FGF7 produce similar responses in the mammary tissue, we conclude that both are acting through the FGFRIIb receptor. Notably, human and murine mammary tissues also respond differently to FGFR2 ligands, as the murine organoids grow and branch with FGF7 alone, in contrast to breastoids. These results differ from those of Fata et al. (2007), as we observed that FGF7 does stimulate branching in organoids isolated from post-pubertal mice, but they are consistent with the earlier work of Sternlicht et al. (2005). Thus, in our experiments, both species require an FGFR2 ligand in combination with a HER1 ligand to obtain a normal ductal structure.

Little is known about the role of extrinsic signaling in controlling lineage specification. Recently, however, the self-renewal of murine mammary stem cells was demonstrated to be under the control of steroid hormone signaling (Asselin-Labat et al. 2010), probably through paracrine signaling from the RANK ligand. In other tissues, EGF signaling was recently found to promote expansion of neural progenitor cells at the expense of neural stem cells (Aguirre et al. 2010), FGF4 is required to induce pluripotent embryonic stem cell differentiation (Lanner and Rossant 2010), and angiocrine factors secreted by endo- thelial cells promote expansion of haematopoeitic stem and progenitor cells (Kobayashi et al. 2010). Intercellular signaling, therefore, may be a common feature by which organisms can acutely regulate the fate of stem and progenitor cells.

A notable feature of the human breastoids grown in the presence of EGF concerns the dynamics of p63 expression. p63 is a marker of mature myoepithelial cells, but also plays key roles in ectodermal progenitor commitment (Senoo et al. 2007). Initially, p63 ${ }^{+}$cells are confined to the myoepithelial cells in close proximity to the extracellular matrix; then, as this lineage expands, the p $63^{+}$cells fill the entire breastoid. These cells are also $\mathrm{K} 4^{+}$, but after long-term culture (29 d), the central cells

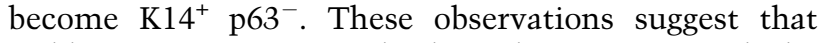
stable p63 expression might depend on contact with the extracellular matrix and require integrin engagement-a conclusion supported by the clonal colony formation assay (Fig. 3C). It remains unclear whether the p63- cells represent a dedifferentiated myoepithelial cell pool or some other cell type, but it is notable that the cells in the CD49f/EpCAM ${ }^{+}$progenitor pool were all p63 ${ }^{-}$.

Our understanding of the function of myoepithelial cells in cancer is extremely limited. Breast tumors composed of fully differentiated myoepithelial cells are rare; however, it is possible that basal-like carcinomas are comprised of precursor cells that would normally give rise to myoepithelial cells (Lim et al. 2010). Given the physical location of the myoepithelial layer, these cells most likely act to facilitate the communication between the luminal layer and the stroma (Barsky and Karlin 2006). It has been proposed that the myoepithelial cells confer polarity to luminal epithelial cells. This hypothesis is based on evidence that normal myoepithelial cells polarized luminal epithelial cells grown in vitro, whereas myoepithelial cells isolated from tumors did not confer polarity in this system (Gudjonsson et al. 2005). In agreement with these results, normal myoepithelial cells suppressed tumor growth and progression in the MCF10DCIS.com xenograft model of human DCIS (Hu et al. 2008). A key future goal will be to determine which targets of RSK control the myoepithelial cell lineage and how myoepithelial cells contribute to cancer.

\section{Materials and methods}

\section{Breastoid purification}

Human breast tissue from reduction mammoplasty or from the normal margin that was removed during breast cancer surgery was collected as waste tissue with institutional review board approval. A list of the age and race for each of the patient samples used in this study is provided (Supplemental Table 1). The tissue was weighed and minced with scissors into $1-\mathrm{mm}^{3}$ portions. A portion was taken for fixing in $10 \%$ formalin (Protocol) for $2 \mathrm{~d}$ and then placed in $70 \%$ ethanol. The fixed samples were paraffin-embedded and $5-\mu \mathrm{m}$ sections were prepared by the University of Virginia Research Histology Core. Tissue was sometimes cryopreserved by adding an equivalent weight of $90 \%$ breastoid base medium (BBM) (DMEM/F12 with 15 mM HEPES at pH 7.4 [Invitrogen] [DMEM/F12], $100 \mu \mathrm{M}$ ethanolamine [Sigma], 
$1 \mu \mathrm{g} / \mathrm{mL}$ hydrocortisone [Sigma], $10 \mu \mathrm{g} / \mathrm{mL}$ insulin $-5.5 \mu \mathrm{g} / \mathrm{mL}$ transferrin- $6.7 \mathrm{ng} / \mathrm{mL}$ selenium [Invitrogen], $100 \mathrm{U} / \mathrm{mL}$ penicillin-100 $\mu \mathrm{g} / \mathrm{mL}$ streptomycin [Invitrogen], $2.5 \mu \mathrm{g} / \mathrm{mL}$ Amphotericin B [Sigma], $50 \mu \mathrm{g} / \mathrm{mL}$ gentamicin [Invitrogen]), $5 \%$ fetal bovine serum (FBS) (Atlanta Biologicals), and 5\% dimethyl sulfoxide. The tissue was thawed at $37^{\circ} \mathrm{C}$ and placed in prewarmed DMEM/F12 before proceeding. Approximately $15 \mathrm{~g}$ of fresh or thawed tissue was digested for $18-21 \mathrm{~h}$ at $37^{\circ} \mathrm{C}$ in a $5 \%$ $\mathrm{CO}_{2}$ incubator with sterile $25 \mathrm{~mL}$ of Collagenase A medium (DMEM/F12, $1 \mathrm{mg} / \mathrm{mL}$ Collagenase A [Roche], $1 \mu \mathrm{g} / \mathrm{mL}$ insulin [Sigma], $600 \mathrm{U} / \mu \mathrm{L}$ Nystatin (Sigma), $100 \mathrm{U} / \mathrm{mL}$ penicillin-100 $\mu \mathrm{g} / \mathrm{mL}$ streptomycin [Invitrogen]). If the sample was very fibrous, additional Collagenase A medium was added at 16-17 h. The digested material was centrifuged at $180 \mathrm{~g}$ for $5 \mathrm{~min}$ and the solubilized material was decanted from the pellet containing the breastoids. The pellet was washed in $5 \mathrm{~mL}$ of prewarmed DMEM/F12 medium. The pellet was resuspended in $5 \mathrm{~mL}$ of prewarmed DMEM/F12 with DNase I (1000 U/mL) (Sigma) for $3-5 \mathrm{~min}$ at $37^{\circ} \mathrm{C}$ in a $5 \% \mathrm{CO}_{2}$ incubator. FBS $(0.5 \mathrm{~mL})$ was added and the suspension was centrifuged at $180 \mathrm{~g}$ for $10 \mathrm{~min}$. The pellet was resuspended in $9 \mathrm{~mL}$ of phosphate-buffered saline (PBS) with 5\% FBS and centrifuged at $350 \mathrm{~g}$ for $15 \mathrm{sec}$. This wash step was repeated six times. Any fibrous tissue was removed manually. The pellet was resuspended in $9 \mathrm{~mL}$ of DMEM/F12 and centrifuged at $350 \mathrm{~g}$ for $15 \mathrm{sec}$. The pellet was resuspended in $1 \mathrm{~mL}$ of BBM. An aliquot was removed and the number of breastoids was counted.

\section{Mouse organoid purification}

Mouse organoids were prepared from 13- to 16-wk-old virgin C3H mice following the protocol described by Hirai et al. (1998) with modification. The second through fifth pairs of mammary glands were removed, minced, and incubated for $1 \mathrm{~h}$ at $37^{\circ} \mathrm{C}$ with agitation (500 rpm) with $12.5 \mathrm{~mL}$ of Collagenase A medium with Collagenase A at a concentration of $2 \mathrm{mg} / \mathrm{mL}$. The cell suspension was treated as described above except that DNase I was added at $2 \mathrm{U} / \mathrm{mL}$ for $1 \mathrm{~min}$.

\section{Breastoid and mouse organoid plating}

A volume of $60 \mu \mathrm{L}$ of a $60 \%$ Matrigel (BD Biosciences) solution in BBM was added into each well of an eight-well LabTek chamber (Thermo Scientific) and allowed to solidify for $15 \mathrm{~min}$ in a $37^{\circ} \mathrm{C}$ $5 \% \mathrm{CO}_{2}$ incubator. In a separate tube, 30-40 medium-sized breastoids or mouse organoids per well were added and the volume was brought up to $40 \mu \mathrm{L}$ using a $50 \%$ Matrigel solution in BBM. This mixture was added to the solidified Matigel and allowed to solidify for $15 \mathrm{~min}$ in a $37^{\circ} \mathrm{C} 5 \% \mathrm{CO}_{2}$ incubator. BBM $(350 \mu \mathrm{L})$ supplemented with growth factors was then added. EGF (Calbiochem), FGF7 (R\&D Systems), AREG (R\&D Systems), NRG1- $\beta 1$ (R\&D Systems), and TGF $\alpha$ (Sigma) were used at $5 \mathrm{nM}$, and FGF2 (R\&D Systems) was used at $1 \mathrm{nM}$ unless stated otherwise. The medium was replaced every 2-3 d. U0126 $(20 \mu \mathrm{M})$ (Sigma) and SL0101 $(100 \mu \mathrm{M})$ were added with fresh medium every $48 \mathrm{~h}$.

\section{Immunostaining}

The breastoids and mouse organoids were washed twice with room-temperature PBS, and $500 \mu \mathrm{L}$ of $4 \%$ paraformaldehyde (PFA) in PBS (4\% PFA) was added. After incubation for 40-50 min at room temperature, the $4 \%$ PFA was removed and sufficient $1.5 \%$ agarose in PBS to cover the Matrigel was added. The solidified agar block was transferred into a cell-safe mesh biopsy capsule (Cancer Diagnostics, Inc.) and added to a $70 \%$ ethanol solution. The samples were paraffin-embedded and 5- $\mu \mathrm{m}$ sections were prepared by the University of Virginia Research Histology Core. The sections were deparaffinized by heating the slides to $50^{\circ} \mathrm{C}$ and placed in SafeClear II twice, for $5 \mathrm{~min}$ and then $3 \mathrm{~min}$, which was followed by $100 \%$ ethanol for $3 \mathrm{~min}$. The ethanol was slowly changed to deionized water by decreasing the percentage of ethanol in a step-wise manner. The slides were immersed in boiling $10 \mathrm{mM}$ TRIS ( $\mathrm{pH} 9.0$ ) and $1 \mathrm{mM}$ ethylenediaminetetraacetic acid for $20 \mathrm{~min}$. After cooling, the slides were rinsed twice with deionized water and three times with PBS.

The deparaffinized sections were blocked in $10 \%$ bovine serum albumin (BSA) in PBS and incubated with primary antibody diluted in $3 \% \mathrm{BSA}$ in $\mathrm{PBS}$ overnight at $4^{\circ} \mathrm{C}$. The sections were washed three times with $3 \%$ BSA in PBS and incubated with secondary antibody diluted in 3\% BSA in PBS for $1 \mathrm{~h}$ at room temperature. The sections were washed twice with PBS and stained with a 1:500 dilution of DRAQ5 (Axxora) for $10 \mathrm{~min}$. After two brief washings with PBS, the coverslips were mounted using Fluoro-Gel (EMS). A list of primary and secondary antibodies, the vendors, and dilutions used in this study is provided (Supplemental Table 9).

\section{Imaging and analysis}

DIC images of breastoids and mouse organoids were obtained with a Zeiss LSM510 Meta/FCS laser-scanning confocal microscope and a $10 \times$ Plan-Neofluar objective (NA 0.30) using a zoom of $0.7 \times$. Images of immunostained sections were obtained with a $40 \times$ Plan-Neofluar oil objective (NA1.3) using a zoom of $0.7 \times$ or $1.5 \times$, and a $100 \times$ Plan-Neofluar oil objective (NA1.3) using a zoom of $0.7 \times$. Size measurements were performed using Zeiss LSM Image Browser 4.2.0.121. Immunofluorescence images were analyzed using Openlab 5.5.0 software. Images were manipulated in Adobe Photoshop CS3 10.0.1. Statistical significance was determined using the one-way analysis of variance (ANOVA) or Student's $t$-test and all $P$-values $\leq 0.01$ were reported. The $F$-test was used to compare the variability within a patient with the variability between patients, and the values obtained and the $F$-critical for a two sided $F$-test at $5 \%$ significance are reported (Supplemental Tables 2-8).

\section{Immunoblotting}

Breastoids were incubated with dispase $(2.5 \mathrm{mg} / \mathrm{mL}$; Roche $)$ in $\mathrm{BBM}$ supplemented with growth factors for $20 \mathrm{~min}$ at $37^{\circ} \mathrm{C}$. The breastoids were combined; washed twice with ice-cold PBS, NaF $(1 \mathrm{mM})$, and $\mathrm{Na}_{3} \mathrm{VO}_{4}(1.25 \mathrm{mM})$; lysed; and immunoblotted; and the immunoblots were analyzed by densitometry (Joel et al. 1998).

\section{Sorting and analysis}

Breastoids were incubated with dispase and resuspended after centrifugation in an equal mixture of $0.5 \%$ trypsin-EDTA (Invitrogen) and $\mathrm{BBM}$ for $5 \mathrm{~min}$ at $37^{\circ} \mathrm{C}$. The breastoids were resuspended after centrifugation in Accumax (Millipore) for $10 \mathrm{~min}$ at $37^{\circ} \mathrm{C}$. After passage through a cell strainer $(80 \mu \mathrm{m})$, the cells were resuspended in PBS and $2.0 \%$ FBS. The cells were blocked and sorted according to the protocol by Lim et al. (2009) using a FACSVantage SE Turbo flow cytometer (Becton Dickinson). Data were analyzed using FACSDiva 6.0 software (Becton Dickinson; Flow Cytometry Core Facility, University of Virginia). An aliquot of the sorted cells was spun onto glass coverslips, fixed, and immunostained (Eisinger-Mathason et al. 2008). Approximately 5000 sorted cells from each of the 


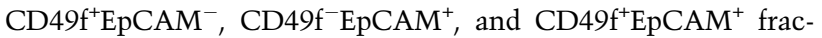
tions were separately plated for analysis in a colony-forming assay in Matrigel as described (Lim et al. 2009), except that the medium was BBM with growth factors. The medium was also supplemented with B27 (Gibco) and, for the first $3 \mathrm{~d}$, with the rho kinase inhibitor Y-27632 (10 $\mu \mathrm{M}$; Tocris Bioscience). The colonies were cultured for $7 \mathrm{~d}$ before fixation, paraffin-embedding, and sectioning.

\section{Acknowledgments}

We especially thank the University of Virginia Research Histology Core and the Biorepository and Tissue Procurement Facility. This work was supported by Susan G. Komen Breast Cancer Foundation FAS0703854 (I.G.M.), NIH grants GM084386 (D.A.L.) and CA132898 (I.G.M.), Patients and Friends of the UVa Cancer Center (D.A.L.), and Swing Fore the Cure (D.A.L.). The cytokeratin Endo-A (K8) monoclonal developed by Philippe Brulet and Rolf Kemler was obtained from the Developmental Studies Hybridoma Bank, developed under the auspices of the NICHD, and maintained by the Department of Biology, University of Iowa, Iowa City, IA.

\section{References}

Aguirre A, Rubio ME, Gallo V. 2010. Notch and EGFR pathway interaction regulates neural stem cell number and selfrenewal. Nature 467: 323-327.

Andrechek ER, White D, Muller WJ. 2005. Targeted disruption of ErbB2/Neu in the mammary epithelium results in impaired ductal outgrowth. Oncogene 24: 932-937.

Asselin-Labat ML, Vaillant F, Sheridan JM, Pal B, Wu D, Simpson ER, Yasuda H, Smyth GK, Martin TJ, Lindeman GJ, et al. 2010. Control of mammary stem cell function by steroid hormone signalling. Nature 465: 798-802.

Baldys A, Gooz M, Morinelli TA, Lee MH, Raymond JR Jr, Luttrell LM, Raymond JR Sr. 2009. Essential role of c-Cbl in amphiregulin-induced recycling and signaling of the endogenous epidermal growth factor receptor. Biochemistry 48: 1462-1473.

Barsky SH, Karlin NJ. 2006. Mechanisms of disease: breast tumor pathogenesis and the role of the myoepithelial cell. Nat Clin Pract Oncol 3: 138-151.

Bouras T, Pal B, Vaillant F, Harburg G, Asselin-Labat ML, Oakes SR, Lindeman GJ, Visvader JE. 2008. Notch signaling regulates mammary stem cell function and luminal cell-fate commitment. Cell Stem Cell 3: 429-441.

Cheon HG, LaRochelle WJ, Bottaro DP, Burgess WH, Aaronson SA. 1994. High-affinity binding sites for related fibroblast growth factor ligands reside within different receptor immunoglobulin-like domains. Proc Natl Acad Sci 91: 989-993.

Clayton H, Titley I, Vivanco M. 2004. Growth and differentiation of progenitor/stem cells derived from the human mammary gland. Exp Cell Res 297: 444-460.

Eisinger-Mathason TS, Andrade J, Groehler AL, Clark DE, Muratore-Schroeder TL, Pasic L, Smith JA, Shabanowitz J, Hunt DF, Macara IG, et al. 2008. Codependent functions of RSK2 and the apoptosis-promoting factor TIA-1 in stress granule assembly and cell survival. Mol Cell 31: 722-736.

Ewald AJ, Brenot A, Duong M, Chan BS, Werb Z. 2008. Collective epithelial migration and cell rearrangements drive mammary branching morphogenesis. Dev Cell 14: 570-581.

Fata JE, Mori H, Ewald AJ, Zhang H, Yao E, Werb Z, Bissell MJ. 2007. The MAPK(ERK-1,2) pathway integrates distinct and antagonistic signals from TGF $\alpha$ and FGF7 in morphogenesis of mouse mammary epithelium. Dev Biol 306: 193-207.
Friedrichs N, Steiner S, Buettner R, Knoepfle G. 2007. Immunohistochemical expression patterns of AP2 $\alpha$ and AP2 $\gamma$ in the developing fetal human breast. Histopathology 51: 814823.

Graham JD, Mote PA, Salagame U, Balleine RL, Huschtscha LI, Clarke CL. 2009. Hormone-responsive model of primary human breast epithelium. J Mammary Gland Biol Neoplasia 14: $367-379$.

Gudjonsson T, Adriance MC, Sternlicht MD, Petersen OW, Bissell MJ. 2005. Myoepithelial cells: their origin and function in breast morphogenesis and neoplasia. I Mammary Gland Biol Neoplasia 10: 261-272.

Haslekas C, Breen K, Pedersen KW, Johannessen LE, Stang E, Madshus IH. 2005. The inhibitory effect of ErbB2 on epidermal growth factor-induced formation of clathrin-coated pits correlates with retention of epidermal growth factor receptor-ErbB2 oligomeric complexes at the plasma membrane. Mol Biol Cell 16: 5832-5842.

Her JH, Lakhani S, Zu K, Vila J, Dent P, Sturgill TW, Weber MJ. 1993. Dual phosphorylation and autophosphorylation in mitogen-activated protein (MAP) kinase activation. Biochem J 296: 25-31.

Hirai Y, Lochter A, Galosy S, Koshida S, Niwa S, Bissell MJ. 1998. Epimorphin functions as a key morphoregulator for mammary epithelial cells. J Cell Biol 140: 159-169.

Hu M, Yao J, Carroll DK, Weremowicz S, Chen H, Carrasco D, Richardson A, Violette S, Nikolskaya T, Nikolsky Y, et al. 2008. Regulation of in situ to invasive breast carcinoma transition. Cancer Cell 13: 394-406.

Jackson-Fisher AJ, Bellinger G, Ramabhadran R, Morris JK, Lee KF, Stern DF. 2004. ErbB2 is required for ductal morphogenesis of the mammary gland. Proc Natl Acad Sci 101: 1713817143.

Joel PB, Smith J, Sturgill TW, Fisher TL, Blenis J, Lannigan DA. 1998. pp90rsk1 regulates estrogen receptor-mediated transcription through phosphorylation of Ser-167. Mol Cell Biol 18: 1978-1984.

Jolicoeur F, Gaboury LA, Oligny LL. 2003. Basal cells of second trimester fetal breasts: immunohistochemical study of myoepithelial precursors. Pediatr Dev Pathol 6: 398-413.

Kobayashi H, Butler JM, O'Donnell R, Kobayashi M, Ding BS, Bonner B, Chiu VK, Nolan DJ, Shido K, Benjamin L, et al. 2010. Angiocrine factors from Akt-activated endothelial cells balance self-renewal and differentiation of haematopoietic stem cells. Nat Cell Biol 12: 1046-1056.

Kuperwasser C, Chavarria T, Wu M, Magrane G, Gray JW, Carey L, Richardson A, Weinberg RA. 2004. Reconstruction of functionally normal and malignant human breast tissues in mice. Proc Natl Acad Sci 101: 4966-4971.

Lanner F, Rossant J. 2010. The role of FGF/Erk signaling in pluripotent cells. Development 137: 3351-3360.

Lim E, Vaillant F, Wu D, Forrest NC, Pal B, Hart AH, AsselinLabat ML, Gyorki DE, Ward T, Partanen A, et al. 2009. Aberrant luminal progenitors as the candidate target population for basal tumor development in BRCA1 mutation carriers. Nat Med 15: 907-913.

Lim E, Wu D, Pal B, Bouras T, Asselin-Labat ML, Vaillant F, Yagita H, Lindeman GJ, Smyth GK, Visvader JE. 2010. Transcriptome analyses of mouse and human mammary cell subpopulations reveal multiple conserved genes and pathways. Breast Cancer Res 12: R21. doi: 10.1186/bcr2560.

Miki T, Bottaro DP, Fleming TP, Smith CL, Burgess WH, Chan AM, Aaronson SA. 1992. Determination of ligand-binding specificity by alternative splicing: two distinct growth factor receptors encoded by a single gene. Proc Natl Acad Sci 89: 246-250. 
Raouf A, Zhao Y, To K, Stingl J, Delaney A, Barbara M, Iscove N, Jones S, McKinney S, Emerman J, et al. 2008. Transcriptome analysis of the normal human mammary cell commitment and differentiation process. Cell Stem Cell 3: 109-118.

Santini D, Ceccarelli C, Tardio ML, Taffurelli M, Marrano D. 2002. Immunocytochemical expression of epidermal growth factor receptor in myoepithelial cells of the breast. Appl Immunohistochem Mol Morphol 10: 29-33.

Schroeder JA, Lee DC. 1998. Dynamic expression and activation of ERBB receptors in the developing mouse mammary gland. Cell Growth Differ 9: 451-464.

Senoo M, Pinto F, Crum CP, McKeon F. 2007. p63 Is essential for the proliferative potential of stem cells in stratified epithelia. Cell 129: 523-536.

Sher I, Lang T, Lubinsky-Mink S, Kuhn J, Adir N, Chatterjee S, Schomburg D, Ron D. 2000. Identification of residues important both for primary receptor binding and specificity in fibroblast growth factor-7. J Biol Chem 275: 34881-34886.

Shoyab M, Plowman GD, McDonald VL, Bradley JG, Todaro GJ. 1989. Structure and function of human amphiregulin: a member of the epidermal growth factor family. Science 243: 1074-1076.

Siegel PM, Muller WJ. 2010. Transcription factor regulatory networks in mammary epithelial development and tumorigenesis. Oncogene 29: 2753-2759.

Simian M, Hirai Y, Navre M, Werb Z, Lochter A, Bissell MJ. 2001. The interplay of matrix metalloproteinases, morphogens and growth factors is necessary for branching of mammary epithelial cells. Development 128: 3117-3131.

Smith JA, Poteet-Smith CE, Xu Y, Errington TM, Hecht SM, Lannigan DA. 2005. Identification of the first specific inhibitor of p90 ribosomal S6 kinase (RSK) reveals an unexpected role for RSK in cancer cell proliferation. Cancer Res 65: 1027-1034

Sternlicht MD, Sunnarborg SW. 2008. The ADAM17-amphiregulinEGFR axis in mammary development and cancer. J Mammary Gland Biol Neoplasia 13: 181-194.

Sternlicht MD, Sunnarborg SW, Kouros-Mehr H, Yu Y, Lee DC, Werb Z. 2005. Mammary ductal morphogenesis requires paracrine activation of stromal EGFR via ADAM17-dependent shedding of epithelial amphiregulin. Development 132: 3923-3933.

Stingl J, Eaves CJ, Zandieh I, Emerman JT. 2001. Characterization of bipotent mammary epithelial progenitor cells in normal adult human breast tissue. Breast Cancer Res Treat 67: 93-109.

Villadsen R, Fridriksdottir AJ, Ronnov-Jessen L, Gudjonsson T, Rank F, LaBarge MA, Bissell MJ, Petersen OW. 2007. Evidence for a stem cell hierarchy in the adult human breast. I Cell Biol 177: 87-101.

Visvader JE. 2009. Keeping abreast of the mammary epithelial hierarchy and breast tumorigenesis. Genes Dev 23: 2563-2577.

Wada T, Qian XL, Greene MI. 1990. Intermolecular association of the p185neu protein and EGF receptor modulates EGF receptor function. Cell 61: 1339-1347.

Wiesen JF, Young P, Werb Z, Cunha GR. 1999. Signaling through the stromal epidermal growth factor receptor is necessary for mammary ductal development. Development 126: 335-344.

Willmarth NE, Baillo A, Dziubinski ML, Wilson K, Riese DJ 2nd, Ethier SP. 2009. Altered EGFR localization and degradation in human breast cancer cells with an amphiregulin/ EGFR autocrine loop. Cell Signal 21: 212-219.

Xian W, Schwertfeger KL, Rosen JM. 2007. Distinct roles of fibroblast growth factor receptor 1 and 2 in regulating cell survival and epithelial-mesenchymal transition. Mol Endocrinol 21: 987-1000.

Xie W, Paterson AJ, Chin E, Nabell LM, Kudlow JE. 1997. Targeted expression of a dominant negative epidermal growth factor receptor in the mammary gland of transgenic mice inhibits pubertal mammary duct development. Mol Endocrinol 11: 1766-1781.

Yalcin-Ozuysal O, Fiche M, Guitierrez M, Wagner KU, Raffoul W, Brisken C. 2010. Antagonistic roles of Notch and p63 in controlling mammary epithelial cell fates. Cell Death Differ 17: $1600-1612$. 


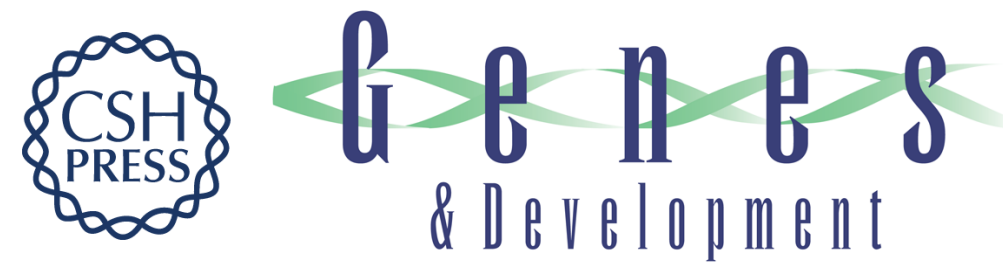

\section{Sustained activation of the HER1-ERK1/2-RSK signaling pathway controls myoepithelial cell fate in human mammary tissue}

Lejla Pasic, T.S. Karin Eisinger-Mathason, Bisi T. Velayudhan, et al.

Genes Dev. 2011, 25:

Access the most recent version at doi:10.1101/gad.2025611

Supplemental http://genesdev.cshlp.org/content/suppl/2011/08/09/25.15.1641.DC1
Material

References This article cites 47 articles, 18 of which can be accessed free at: http://genesdev.cshlp.org/content/25/15/1641.full.html\#ref-list-1

License

Email Alerting Receive free email alerts when new articles cite this article - sign up in the box at the top Service right corner of the article or click here.

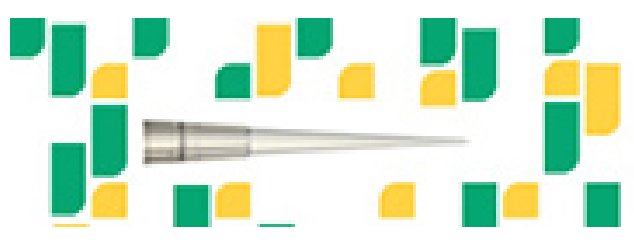

Focused on your science. 